\title{
Physical-Mechanical Properties Variation with Strengthening Polymers
}

\author{
Ş. KILINÇARSLAN* AND Y. ŞIMŞEK TÜRKER \\ Suleyman Demirel University, Department of Civil Engineering
}

\begin{abstract}
Physical and mechanical properties of the materials are very important, especially when used for construction. Wood is a building and engineering material that has been in society for thousands of years with many positive properties, and still maintains its importance. As one knows, wood material loses its strength properties over time and requires maintenance/repair. There are many maintenance and repair methods along with reinforcement with the most commonly used steel elements. Although steel dowels and plates have been used in modern fastening systems recently, there are still some problems regarding the use of steel. It is stated that there are relevant problems especially in the recycling of the material. For this reason, in this study, the aim was to make an ideal reinforcement using non-metallic materials. Larix wood type beam, which is mostly used in the production of all kinds of carrier structural elements and in many other areas, was wrapped with Fibre Reinforced Polymers (FRP). After the winding proccess, the beams were subjected to bending test. After the experimental studies, wood beams were modeled in ANSYS Software Analysis Program and the behavior of FRP wrapped beams against bending was examined. It was found that reinforcement with FRP increases the load bearing capacity and displacement of the beams. Furthermore, it was seen that the results of static analysis with modeling in finite elements give compatible results.
\end{abstract}

DOI: 10.12693/APhysPolA.137.566

PACS/topics: Fibre Reinforced Polymers, Beams, ANSYS, Reinforment

\section{Introduction}

Wood has been used in various fields for many years because of many positive properties. It is known as a building material that attracts great attention especially in construction projects all over the world. Positive properties of wood material include lightweight, manufacturing ease, and environmental friendliness. The most important disadvantages of this material are being hygroscopic material and lacks of resistance to pests $[1,2]$. As a result of unfavorable factors, it degrades over time and loses its strength, and the service life of the material decreases. For this reason, the studies on maintenance and repair of existing carrier elements, especially in wooden structures, are quite high, and it is important to strengthen these structures. Therefore, it is crucial to examine different strengthening techniques that apply to buildings. Timber structures are traditionally reinforced with steel and wood material pieces [3]. One of the current applications commonly used for reinforcement is the one with Fibre Reinforced Polymers (FRP) [4-6]. It is a material that is used in heavy industries due to its resistance to corrosion compared to its weight, good durability, and high fatigue.

In recent years many studies have examined the bending behaviour of wooden beams reinforced with FRP composite materials. Researchers have applied FRP composite materials to reinforce wood carrier elements in

\footnotetext{
* corresponding author; e-mail:

semsettinkilincarslan@sdu.edu.tr
}

different areas of structures [7-10]. The first research studies on the behavior of wood elements reinforced with FRP appeared in the sixties [7, 11]. In these studies, they used glass fibre composites to reinforce solid wood beams. Spaun (1981) [12] tested the increase of stiffness and bending strength in reinforced concrete beams. Then, the use of fibre-reinforced composites on wooden beams was studied $[13,14]$.

In this study, Larix wood type beam, which is mostly used in the production of all kinds of carrier structural elements, as well in many different areas was wrapped with FRP. After the winding process, the beams were subjected to bending test. Next, after the experimental studies, wood beams were modeled in ANSYS Software Analysis Program, and the behavior of FRP wrapped beams against bending was examined.

\section{Materials and method}

Larix beams used to investigate the effect of reinforcement with fibre reinforced polymers on mechanical properties were obtained from Nasreddin Forest Product (Naswood). From the beams with dimensions of $100 \times 100 \times 750 \mathrm{~mm}, 2$ beams were wrapped and 2 beams were not made. Larix beams used to investigate the effect of reinforcement with FRP on mechanical properties were obtained from Nasreddin Forest Product (Naswood). Before the Larix beams were subjected to the bending test, $65 \%$ relative humidity was kept in the air conditioning cabinet until the equilibrium humidity reached $12 \%$ at $25^{\circ} \mathrm{C}$. Technical characteristics of the carbon fibre fabric used in the reinforcement process are given in Table I. 
TABLE I

Technical characteristics of FRP fabric used for reinforcement.

\begin{tabular}{l|c}
\hline \hline \multicolumn{1}{c}{ Code } & $300 / 50$ CFS \\
\hline weight $\left[\mathrm{g} / \mathrm{m}^{2}\right]$ & 300 \\
material structure & carbon \\
modulus of elasticity [MPa] & 230,000 \\
tensile strength [MPa] & 4900 \\
design section thickness [mm] & 0.166 \\
elongation at treak [\%] & 2.1 \\
width [mm] & 500
\end{tabular}
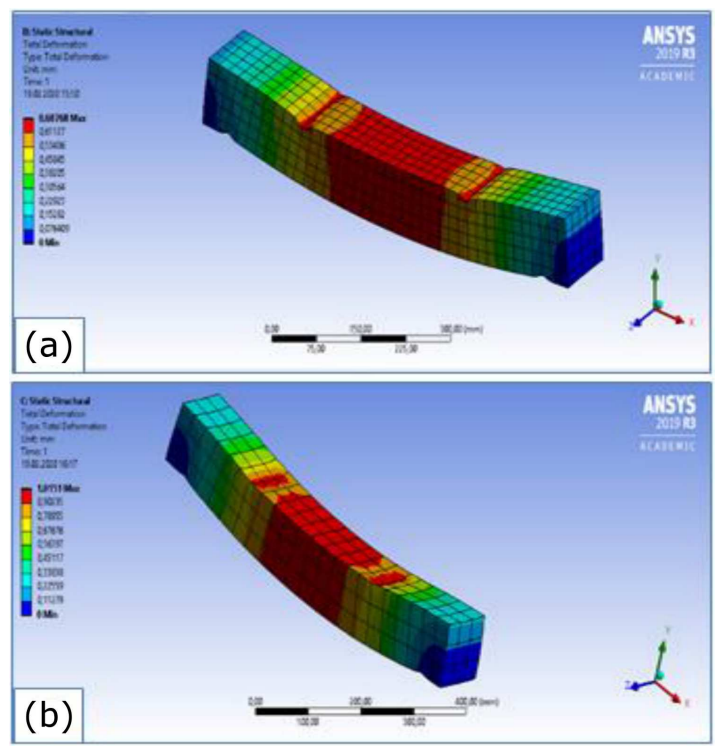

Fig. 1. ANSYS analysis results of beams with FRP application in 2 layers (a) Unreinforced beam with FRP, and (b) Reinforced beam with FRP.

After the winding process was completed, the samples were subjected to a 4-point bending test. The loading device used according to TS EN 408: 2011 has the capacity to measure the load applied to the test piece with an accuracy of $1 \%$. Flexural tests of beams were made and load-displacement graphs were examined. Flexural test analyses were made by modelling with ANSYS Analysis software, which is the finite element software of wood beams. The images of the analysed samples in the ANSYS Software are shown in Fig. 1.

The results of the analysis made in ANSYS Software are compared with the results of static analysis. Loaddisplacement graphs were plotted as a result of static analysis and finite element analysis.

\section{Results}

Two of the four beams were reinforced, and the remaining two beams were subjected to bending test without reinforcement. Load-displacement graphs of Larix beams tested after reinforcement are given in Fig. 2. It is seen

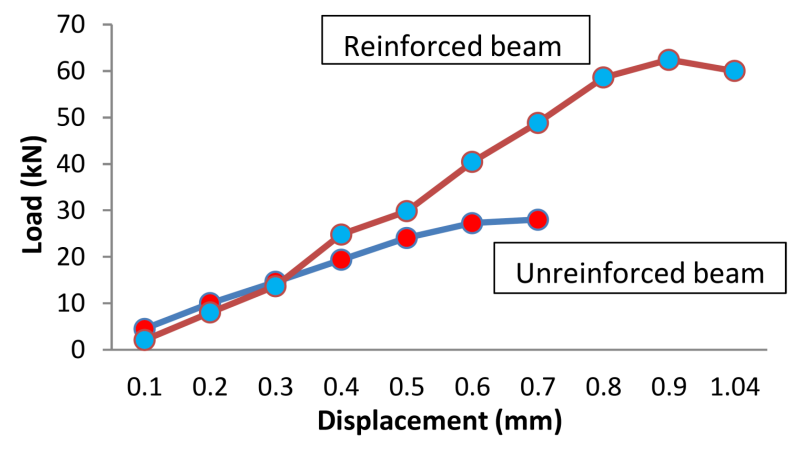

Fig. 2. The load-displacement graph of the two-layer FRP reinforced beam.

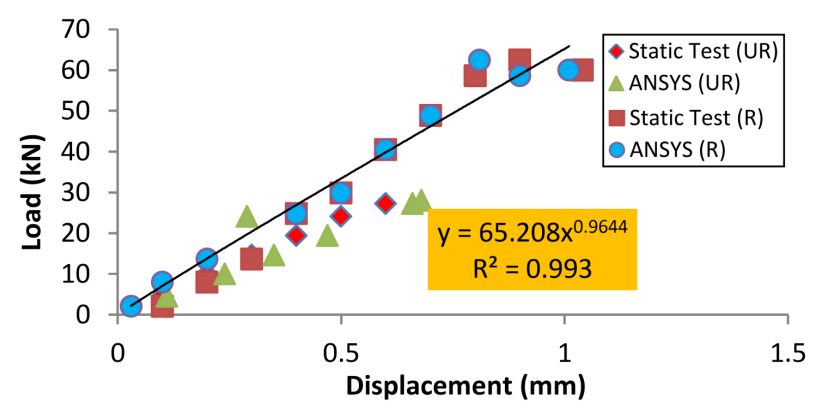

Fig. 3. Comparison of finite elements and static analysis results.

that the load bearing capacity of the beam is higher after being reinforced with fibre reinforced fabric. In addition, it is seen in Fig. 2 that the displacement amount especially formed is higher than the non-reinforced beam element.

Finite element analysis results made in ANSYS Software are compared with static analysis results, as shown in Fig. 3. The correlation between the finite element model and the static analysis results was found to be very high $\left(R^{2}=0.99\right)$.

\section{Conclusion}

Nowadays, FRP application is carried out to reinforce existing wood structures or strengthen historical structures. In this study, the effect of FRP fabrics, which are easy and simple to apply, on the bending behaviour of the solid beam was investigated. The load carrying capacity of the solid wood beam with FRP application was found to be higher than that of the unwrapped solid wood beam. In addition, it was observed that the amount of displacement increased significantly with FRP reinforcement. It was found to perform successfully in wood applications. Finite element modelling and static analysis results showed high correlation between these two analyses. Simulation of the Larix beam wrapped with FRP was provided with the modelling. Therefore, in the prepared model, the bending properties of the FRP reinforced Larix beam could be analysed. 


\section{Acknowledgments}

This study has been prepared within the scope of the thematic area of "Sustainable Building Materials and Technologies" with SDÜ BAP project with FDK-20196950 project code and YÖK 100/2000 doctoral program. The authors thank the SDU BAP unit, YÖK and YÖK $100 / 2000$ program staff.

\section{References}

[1] Ş. Kılınçarslan, Y. Şimşek Türker, in: Proc. of 2nd International Turkish World Engineering and Science Congress Turkey, 2019.

[2] C. Issa, Z. Kmeid, Constr. Build. Mater. 19, 99 (2005).

[3] C. González Bravo, PhD Thesis, E.T.S. of Architecture, Polytechnic University of Madrid, 2007.

[4] Y.A.Z. Ali, Ain Shams Eng. J. 9, 3419 (2018).
[5] B. Wang, E.V. Bachtiar, L. Yan, B. Kasal, V. Fiore, Polymers 11, 1255 (2019).

[6] A. Nair, C.S. Cai, X. Kong, S. Hou, J. Aerospace Eng. 32, 04019065 (2019).

[7] EJ. Biblis, Forest Prod. J. 15, 81 (1965).

[8] J.W.G. Van de Kuilen, in: Proc. of Int. Timber Eng. Conf., London, 1991, Vol. 3, p. 3.226.

[9] D.J. Gardner, J.F. Davalos, Forest Prod. J. 44, 62 (1994).

[10] J.R. Gilfillan, S.G. Gilbert, D.P. Russell, Struct. Eng. 79, 23 (2001).

[11] T.H. Theakston, Can. Agric. Eng. J. 1, 17 (1965).

[12] F.D. Spaun, "Reinforcement of Wood with Fibreglass", 1981.

[13] N. Plavris, T.C. Trintafillou, J. Mater Civ. Eng. 4, 300 (1992).

[14] T. Triantafillou, N. Deskivic, ASCE J. Struct. Eng. 118, 1270 (1992). 